\title{
A Three-Axial Frequency-Tunable Piezoelectric Energy Harvester Using a Magnetic-Force Configuration
}

\author{
Tien-Kan Chung, Chieh-Min Wang, Po-Chen Yeh, Tzu-Wei Liu, Chia-Yuan Tseng, and Chin-Chung Chen
}

\begin{abstract}
To date, researchers have utilized energy harvesters to power wireless sensor nodes as self-powered wireless sensors to create many innovative wireless sensors network applications such as medical monitoring, machining-condition monitoring, and structural-health monitoring. Regarding to energy harvesters, some researchers demonstrated wideband or frequency up-converted vibrational energy harvesters using magnetic force together with piezoelectric materials. However, these harvesters are not able to harness 3-D or three-axial mechanical energy through using one single mechanism or configuration. To address this problem, we report a novel magnetic-force-configured threeaxial frequency-tunable piezoelectric energy harvester in this paper. Due to the magnetic-force configuration, the harvester converts ambient three-axial mechanical vibration/motion to piezoelectric voltage-response (i.e., three-axial energy harvesting). Simultaneously, the harvester also converts the ambient vibration/motion at a lower frequency to higher frequency without mechanical wear-out (i.e., noncontact frequency up-conversion). Through modifying the configuration, the oscillating frequency is tunable. By frequency tuning, the harvester's oscillating frequency and ambient vibration frequency are able to be matched to maximize the power output. Experimental results show the peak voltage, peak power, and frequency conversion of one single piezoelectric beam of the harvester under an in-plane and out-of-plane vibration is up to $800 \mathrm{mV}, 640 \mathrm{nW}$, and from 7 to $56 \mathrm{~Hz}$, and $27 \mathrm{mV}, 729 \mathrm{pW}$, and from 1 to $294 \mathrm{~Hz}$, respectively. These results confirm the harvester is capable of harnessing energy from 3-D and three-axial mechanical motion/vibration, addressing frequency-mismatching issue, avoiding mechanical wear-out problems, and producing a stable voltage output. Due to these, the energy-harvesting approach will enable more novel and practical wireless sensors network applications in the future.
\end{abstract}

Index Terms-Magnetic, piezoelectric, 3-axial, 3-dimensional, frequency tunable, energy harvester, wireless sensor.

\section{INTRODUCTION}

$\mathbf{T}$ O DATE, researchers have utilized Wireless Sensors Network (WSN) [1] to several applications such as medical monitoring [2]-[4], machining-condition monitoring [5], [6], and structural-health monitoring [7]. For these

Manuscript received January 24, 2014; revised April 10, 2014; accepted May 5, 2014. Date of publication May 19, 2014; date of current version July 25, 2014. This work was supported by the Taiwan Ministry of Science and Technology under Grant 102-2221-E-009-034 and Grant 102-2625-M-009-005. The associate editor coordinating the review of this paper and approving it for publication was Dr. Kailash Thakur.

The authors are with the Department of Mechanical Engineering, National Chiao Tung University, Hsinchu 30010, Taiwan (e-mail: tkchung@nctu.edu.tw; chmin0217@gmail.com; scarletleaf203@gmail.com; f890605@gmail.com; zxc351763x@yahoo.com.tw; aew854262@gmail.com).

Color versions of one or more of the figures in this paper are available online at http://ieeexplore.ieee.org.

Digital Object Identifier 10.1109/JSEN.2014.2325675 applications under some situations, numerous wireless sensors are required to be implanted in a human body or embedded into the mechanical structure and civil infrastructures. However, after the sensors are implanted, the battery charging and replacing become difficult. One of the solutions to address this problem is "self-powered" sensors. Toward the self-powered sensors for WSN, researchers demonstrated using vibrational energy harvester [8], [9] as an alternative or complementary energy solution to power the sensors when the ambient vibration sources are available [10]-[18]. That is, the sensors are directly powered or the battery of the sensors is charged by the electrical energy which is converted from the ambient vibrational/mechanical energy by the harvesters.

Recently, researchers showed a 3-dimensional (3-D) capacitive energy harvester utilizing the concept of 3-D MEMS capacitive accelerometers [19]. However, a voltage bias is needed to enable the capacitive harvester resulting in more power consumption. To address this issue, some researchers demonstrated a novel 3-D capacitive energy harvester using electrets [20], [21]. The fundamental concept of the electretbased harvester is similar as the 3-axial MEMS capacitive accelerometers but using the electrets can avoid the need of the voltage bias. Although the 3-D electret-based harvesters are more practical and helpful to the sensors when 3-D motion/vibration resources are available to be harnessed, the stability, durability, and charging problem of the electrets of the harvester should be considered when the harvester is used under a harsh environment/condition or long-term operation. In addition, because the resonant frequency of the 3-D harvesters and the vibrational frequency of the ambient vibration are not matched, the power-output of the harvesters is not maximized [22], [23]. Due to these, researchers are still searching an alternative frequency-tunable $3-\mathrm{D}$ vibrational energy harvester to avoid using these capacitive/electret-based energy harvesters.

Regarding to frequency-tunable energy harvesters, some researchers demonstrated wideband or frequency up-converted vibrational energy harvesters using magnetic-force together with piezoelectric materials [24]-[32]. However, these harvesters are not able to harness 3-D or 3-axial mechanical energy through using one single mechanism or configuration. Toward frequency-tunable 3-D vibrational energy harvesters, we recently demonstrated a frequency up-converted magneticforce-configured piezoelectric energy harvester [33] capable of converting a horizontal axial (in-plane) motion/vibration 
to a vertical axial (out-of-plane) motion/vibration through a novel mechanism and consequently producing voltageresponse due to the piezoelectric effect. In addition to this, other researchers showed novel electromagnetic and piezoelectric energy harvester converts a vertical axial (out-of-plane) motion/vibration at a lower frequency to induce another vertical axial (out-of-plane) motion/vibration at a higher frequency and subsequently generate voltage-response through the electromagnetic induction and piezoelectric effect, respectively [34]-[38]. More recently, utilizing the concept of these frequency-conversion approaches, we successfully demonstrated a 3-D magnetic-piezoelectric energy harvester with a non-contact frequency-conversion approach [39]. Although the 3-D energy harvester we presented is capable of harnessing energy from 3-D mechanical motion and addressing the frequency-mismatching problem, the voltage output of the harvester under the in-plane vibration is unstable due to the chaos motion of the glider of the harvester (i.e., caused by the un-constrained mechanism of the harvester). In addition, due to this chaos motion, the frequency-converting factor (i.e., defined as the ratio of the converted to unconverted frequency) during the frequency-converting process is not as exact as we designed. That is, the frequency is not exactly converted in proportional to the number of the magnets used by the harvester for frequency-conversion. Due to the unstable voltageoutput and inaccurate frequency-conversion, researchers utilizing this 3-D harvester would have a difficulty on modulating the voltage-response to steadily power the commercial electronics. To address this problem, a 3-D harvester capable of producing a stable power-output is needed. Hence, in this paper, we modify the magnetic-force-configuration by adding more magnetic force interactions to constrain the motion of the glider of the harvester in order to modify our previous 3$\mathrm{D}$ harvester to a 3-axial harvester. Due to the well-constrained motion of the glider of the 3-axial harvester, a more stable voltage-response of the harvester is steadily produced and subsequently the more accurate frequency-conversion is achieved. In addition, through the non-contact frequencyconversion approach, both the frequency-mismatching and wearout problems of the harvesters utilizing typical contactbased frequency-conversion are solved [34]-[38].

\section{DESIGN}

The magnetic-force-configured 3-axial frequency-tunable piezoelectric energy harvester is illustrated in Fig 1. In Fig. 1(a)-(c), the harvester consists of piezoelectric cantilever beams with a magnet attached on the free end of each beam, a magnetic glider with a magnet array and mechanical springs fixed on the surface and sidewall of the glider, respectively, four constraining-magnets fixed on the top frame to produce magnetic repulsive force to precisely constrain the motion of the glider, and a mechanical frame assembling the piezoelectric beams, magnetic glider, and constrainingmagnets.

When the harvester experiences the horizontal x-axial ambient vibration (i.e., vibration along $\mathrm{x}$-axis direction in an in-plane) as shown in Fig. 2(a)-(j), a magnetic repulsive force
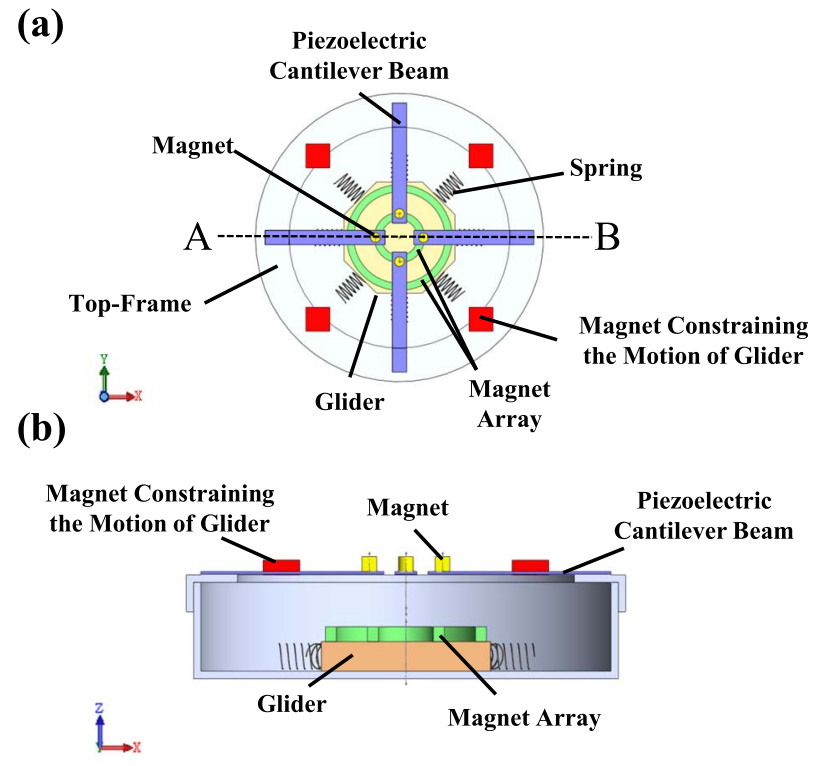

(c)

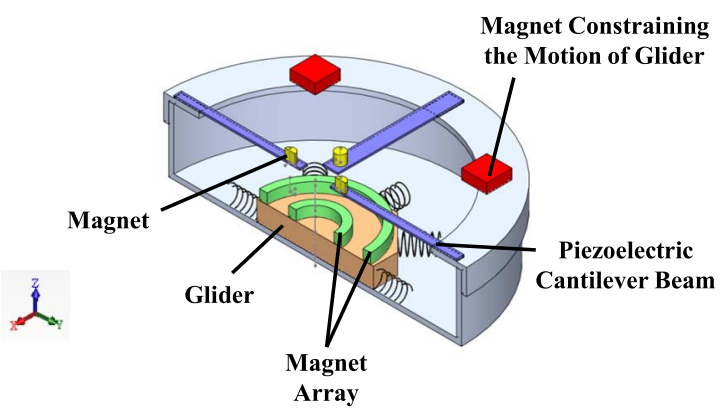

Fig. 1. (a) The top view of the 3-axial frequency-tunable energy harvester. (b) The cross-sectional and (c) isometric view along the A-B dash-line in (a). A specific magnetic repulsive force which is produced between the magnets fixed on the glider and the constraining-magnets fixed on the top frame enforces the glider translating along the $\mathrm{x}$-axis or $\mathrm{y}$-axis in the horizontal plane.

which is produced between the additional four magnets (i.e., constraining-magnets) fixed on the top frame and magnet array fixed on the glider enforces the glider to move (oscillates) along the horizontal $\mathrm{x}$-axis only. Because the base of each piezoelectric beam is fixed on the frame, the moving (oscillation) of the glider produces a relative motion between the glider and each beam. When the glider translates beneath each piezoelectric beam, each beam vibrates accordingly due to another magnetic repulsive-force interaction between the magnet on the beam and the magnet-array on the glider and subsequently generates voltage-response due to the piezoelectric effect. In addition to the energy-harvesting from the inplane motion, the frequency of harvester is tunable through the frequency-conversion approach, shown in Fig. 2(k)-(o). Fig. 2(k)-(o) show the expected voltage-response of each piezoelectric beam of the harvester under the in-plane vibration. When a magnet fixed on the glider translates toward (but not close to) the magnet fixed on the beam as shown in Fig. 2(f), the magnetic force generated between the magnets on the beam and glider is too small to deflect the beam. Thus, no deflection of the beam produces voltage-response as shown in Fig. 2(k). When the magnet fixed on the glider approaches 

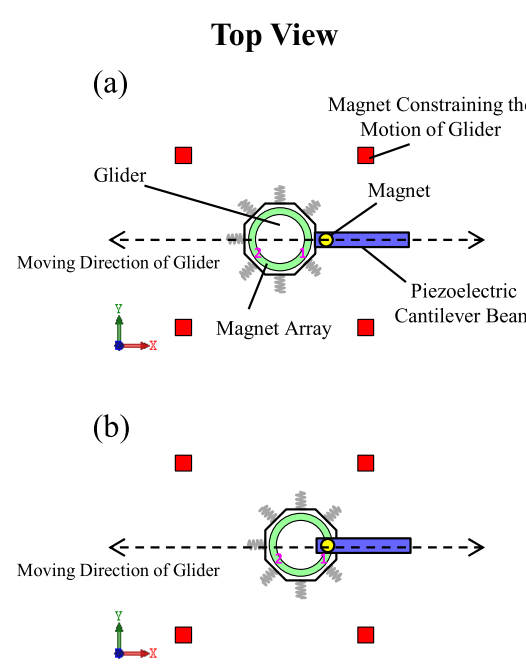

(c)

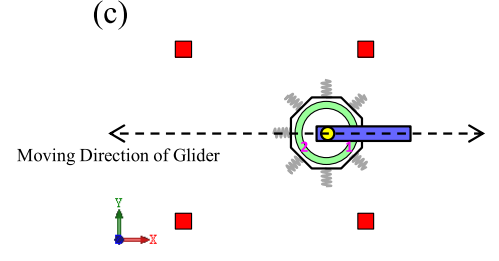

(d)

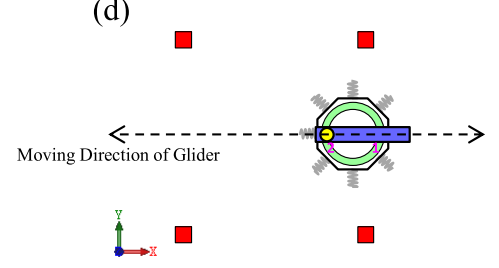

(e)

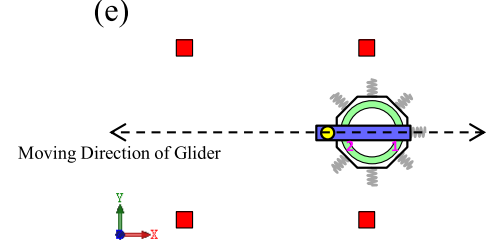

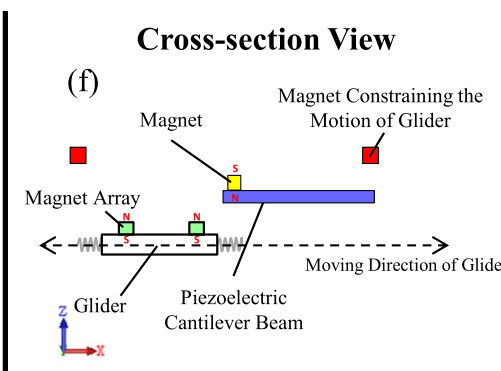

(g)

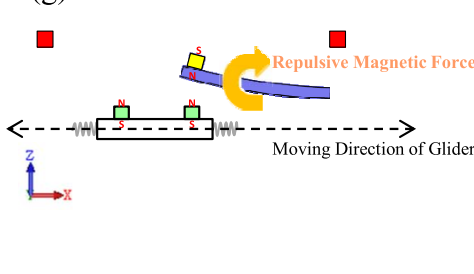

(h)

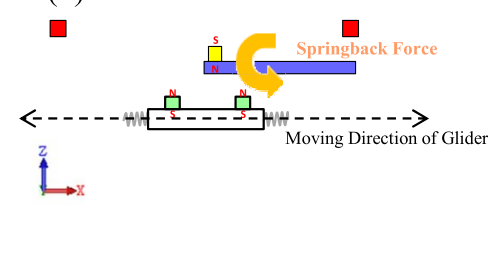

(i)

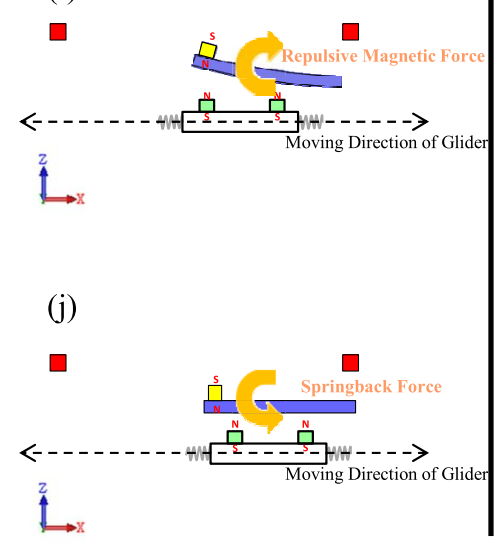

Output Voltage Waveforms

(k)

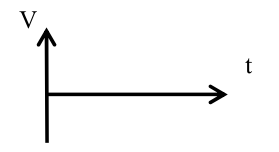

(1)

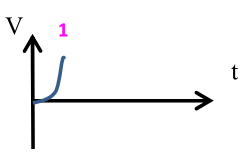

(m)

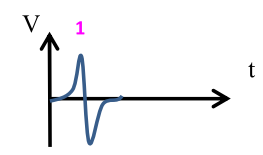

(n)

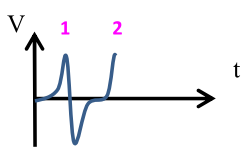

(o)

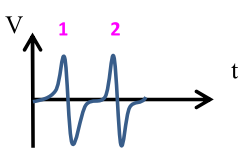

Fig. 2. The illustration of the harvester demonstrating the energy-harvesting from the horizontal $x$-axial (in-plane) mechanical motion (note: can be from the x-axial or y-axial in a horizontal-plane motion because the structure of the harvester is symmetric) and frequency-tuning through the frequencyconversion approach. (a)-(e) Top view and (f)-(j) cross-sectional view of the moving of the glider in the harvester under the x-axial (in-plane) motion/vibration. (k)-(o) Expected voltage-response of the harvester.

(close to) the magnet on the beam as shown in Fig. 2(g), the magnetic repulsive force between the magnets is increased. This results in increasing the deflection of the beam. Therefore, a voltage-response is produced and gradually increased to the maximum response as shown in Fig. 2(1). When the magnet on the glider translates away from the magnet on the beam as shown in Fig. 2(h), the magnetic repulsive force is decreased. Due to this, the deflection of the beam is decreased and subsequently the voltage-response is decreased as shown in Fig. 2(m). If there are several magnets fixed on the glider and the glider is translated passing the beam once (i.e., in each cycle of the in-plane vibration), the beam is deflected several times depending on (and in proportional to) the number of magnets on the glider translating beneath the beam, as shown in Fig. 2(f)-(j). Thus, several peaks of the voltage-response are produced as shown in Fig. 2(k)-(o). Therefore, the number of magnetic elements on the glider determines the number of magnetic repulsive-force interactions subjecting to each piezoelectric beam in each cycle of the in-plane vibration. When the number of magnetic elements on the glider is increased, the oscillating cycles (i.e., oscillating frequency) of each beam of the harvester is increased. Due to this, the ambient incoming lower vibration frequency is expected to be converted up to a higher frequency (i.e., ambient incoming lower vibration frequency $\mathrm{x}$ number of magnetic elements on the glider passing beneath the piezoelectric beam $=$ expected 


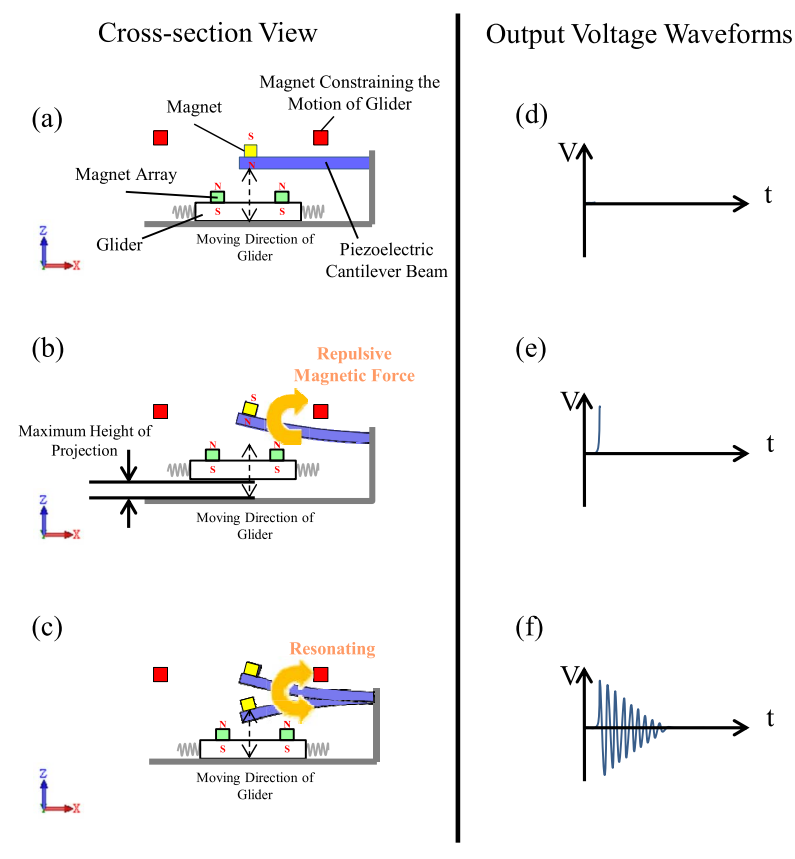

Fig. 3. The illustration of the harvester demonstrating the energy-harvesting from the vertical z-axial (out-of-plane) mechanical motion/vibration and frequency-tuning through a frequency-up conversion approach. (a)-(c) Crosssectional view of the moving of the glider in the harvester under the z-axial (out-of-plane) motion/vibration. (d)-(f) Expected voltage-response of the harvester.

converted-frequency). This achieves frequency-up conversion. Furthermore, through modifying the magnetic-force configuration (i.e., modifying the magnetic force interaction subjecting to the piezoelectric beam), the oscillating-frequency of the harvester is not only convertible but also tunable.

When a vertical z-axial (out-of-plane) ambient vibration is applied by the shaker to the harvester, the glider of the harvester is vertically projected up-and-down/reversely along the z-axis shown in Fig. 3.

In the beginning shown in Fig. 3(a), the glider is static before the vibration is applied to the harvester. As shown in Fig. 3(b), when the glider is projected vertically upward/toward a piezoelectric beam with a magnet fixed on the free end of the beam, the beam experiences a magnetic repulsive-force interaction produced between the magnet-array on the glider and the magnet on the beam. Due to the repulsive interaction, the beam is deflected accordingly. Consequently, voltage-response is produced due to the piezoelectric effect as shown in Fig. 3(e). As shown in Fig. 3(c), after the glider is projected, eventually the glider lands on the bottom-frame due to the gravity. When the glider is away from the beam due to the landing, the magnetic repulsive-force subjected to the beam is decreased (i.e., the force which deflects the beam is decreased). When the magnetic repulsive-force deflecting the beam is lower than the spring-back force of the beam, the deflected beam is released and consequently is oscillated along the vertical z-axial (outof-plane) direction. The oscillated beam produces continuous voltage-responses shown in Fig. 3(f). This demonstrates that the harvester harnesses the mechanical energy from the vertical
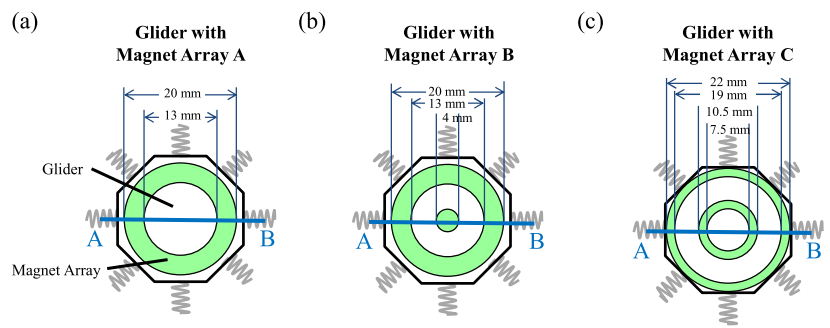

Fig. 4. (a)-(c) Three different designs of magnet arrays fixed on the glider of the harvester.

z-axial (i.e., out-of-plane) mechanical motion and subsequently converts the mechanical energy to the electrical energy. In each cycle of the vertical z-axial (out-of-plane) vibration shown in Fig. 3(a)-(c), the ambient lower incoming vibration frequency is up-converted to resonate the harvester as shown in Fig. 3(d)-(f). Due to this, the oscillating cycles/frequency of the harvester is increased. This means the harvester we designed is able to achieve the frequency-conversion for vertical $\mathrm{z}$-axial (out-of-plane) motion/vibration.

Furthermore, through modifying the magnetic-force configuration of the harvester (i.e., varying geometry/ size/arrangement of the magnet-array on the glider and changing relative location between the magnet-array on the glider and the magnet on the piezoelectric beam), the converted oscillating-frequency/cycles of the harvester under the in-plane and out-of-plane vibration/motion is controlled and tuned. Among parameters of modifying the magneticforce configuration, the magnet-array fixed on the glider of the harvester significantly dominates both the magnetic force interaction and frequency-conversion which consequently influence the power-output of the harvester. Therefore, three different magnet arrays fixed on the glider of the harvester, illustrated in Fig. 4, are investigated to study how the magnet arrays determine the converted oscillating-frequency of the harvester.

In addition, the magnetization of the magnet array on the glider and magnet on the beam is set as opposite. This produces a magnetic repulsive-force interaction between the magnet-array on the glider and magnet on the beam. Hence, the frequency-conversion of our harvester is a noncontact approach which solves the wear problem occurred in typical frequency-up conversion utilizing a mechanicalcontact mechanism [34]-[38]. Due to these above-mentioned capabilities of energy-harvesting and frequency-converting from the x-axial, y-axial (in-plane), and z-axial (out-of-plane) motions/vibration, the harvester we designed is a 3 -axial frequency-tunable energy harvester.

\section{FABRICATION AND TESTING}

According to the design, the harvester we fabricated is shown in Fig. 5.

Each of the piezoelectric beams (length $\times$ width $\times$ thickness: $20 \mathrm{~mm} \times 3 \mathrm{~mm} \times 250 \mu \mathrm{m}$ ) of the harvester is fabricated by altering a PZT-5H plate. A Neodymium 


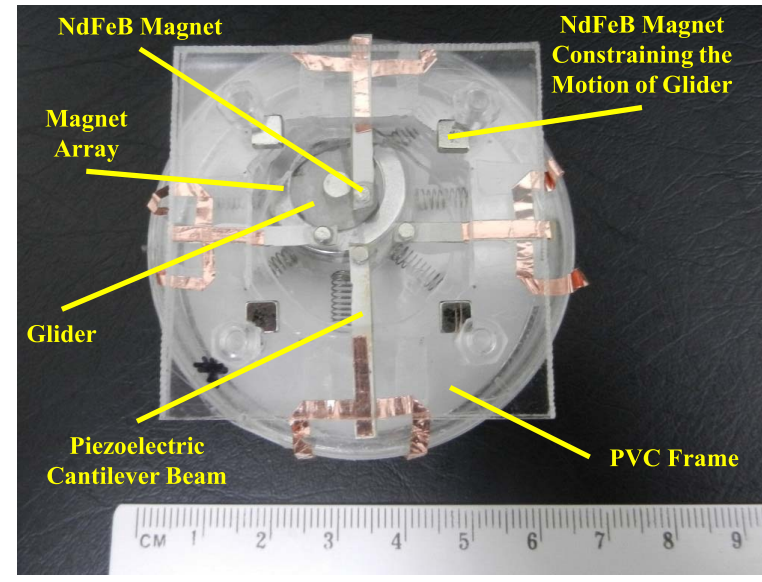

Fig. 5. The photograph (top-view) of the 3-axial frequency-tunable energy harvester utilizing the magnetic-force configuration with piezoelectric beams

Iron Boron $(\mathrm{Nd}-\mathrm{Fe}-\mathrm{B})$ disk-magnet (diameter $\times$ thickness: $2 \mathrm{~mm} \times 2 \mathrm{~mm}$ ) is fixed on the free-end of each beam. The base of each beam is fixed on the top mechanical-frame which is altered from a Polyvinyl Chloride plate. Nd-Fe-B magnet arrays (see Fig. 4 for the information of geometry and dimension) and mechanical spring is attached to the surface and sidewall of a Polymethylmethacrylate disk, respectively, as the magnetic glider. After this, the glider is lubricated and set on the bottom mechanical-frame. Furthermore, the topand bottom- mechanical frames are assembled. Finally, the additional $\mathrm{NeFeB}$ constraining-magnets which constrain the motion of the glider are fixed on the top mechanical-frame.

The voltage output of the 3-axial frequency-tunable energy harvester is tested by vibration shakers with the horizontal $\mathrm{x}$-axial (in-plane) and vertical z-axial (out-of-plane) vibration modes. An illustration of the horizontal x-axial (in-plane) and vertical $\mathrm{z}$-axial (out-of-plane) vibration test is shown in Fig. 6(a) and 6(b), respectively. In the horizontal x-axial (in-plane) vibration test, the harvester is fixed on the surface of the shaking-plate of a reciprocating-horizontal controllable shaker and oscillated along the horizontal x-axial (in-plane) with the shaker.

For the vertical z-axial (out-of-plane) vibration test, the harvester is set on the surface of the shaking-plate of a Ling Dynamic System (LDS) shaker. A function generator and power amplifier are used to provide a voltage signal to the LDS shaker in order to generate a vertical z-axial (out-of-plane) vibration to the harvester. An oscilloscope is used to record the voltage response of the energy harvester. The equivalent load resistance is $10^{6} \Omega$.

After the voltage response is obtained. The power output is extimated through the equation $\mathrm{P}=\mathrm{V}^{2} / \mathrm{R}$ [40].

\section{RESULTS AND DiscUSSION}

Three different magnet arrays (see Fig. 4 for the geometric/dimensional information) fabricated/fixed on the glider (i.e., as magnetic glider) are shown in the inset of Fig. 7(a)-(c). In Fig. 7(a)-(c), the magnetic field generated by the magnet fixed on the glider is measured by the gauss meter (a)

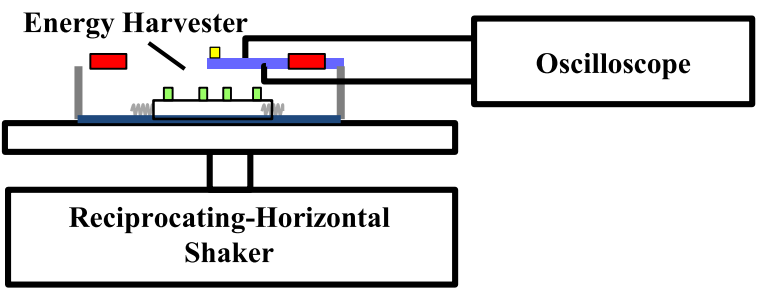

(b)

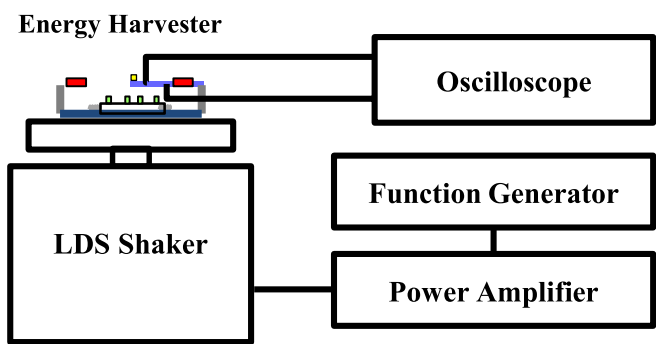

Fig. 6. The illustration of the (a) in-plane and (b) out-of-plane vibration tests.

placing at the location of the free-end of the representative one of the piezoelectric beams. That is, we measured magneticfield profile along line A-B, shown in the inset of Fig. 7(a)-(c), at the location of the free-end of the piezoelectric beam. According to Fig. 7(a)-(c), the measured magnetic field right above the central location of each magnet-element is relatively higher than the field at other locations. The higher magnetic field indicates that the magnetic repulsive force between the magnet-array fixed on the glider and the magnet fixed on the piezoelectric beam is higher. Thus, a larger deflection of the beam is caused by the larger magnetic repulsive force. Due to this, the alternative larger and smaller magnetic field indicates the alternative larger and smaller magnetic force subjected to the beam and consequently induces the alternative larger and smaller deflection of the beam. Therefore, when an $\mathrm{x}$-axial in-plane vibration is applied to the harvester, the glider is translated beneath the beam periodically. When the glider is translated beneath the beam in each cycle, the beam is periodically deflected several times (depending on the number of the magnet-elements in the magnet array fixed on the glider passing beneath the piezoelectric beam). That is, the lower oscillating-frequency of the glider is up-converted to the higher oscillating frequency of beam Due to these, Fig. 7(a)-(c) show the three different magnetic gliders (magnet array A, $\mathrm{B}$, and $\mathrm{C}$ fixed on the glider) we fabricated are capable of generating periodical magnetic field to the piezoelectric beam and consequently are able to achieve the frequency-conversion (as we designed in Fig. 2(f)-(o)). That is, the ambient lower $\mathrm{X}$-axial (in-plane) vibration frequency is expected to be converted by the harvester consisting of the magnet array $\mathrm{A}, \mathrm{B}$, and $\mathrm{C}$ to a 4-, 6-, and 8- times higher frequency, respectively. In addition, we noticed in the case of the magnet array $\mathrm{C}$ (the width of the ring magnet is shorter and the magnetarrangement is more compact and dense than the other magnet arrays), the magnitude of the magnetic field (i.e., produced by the central and other section of the magnet array $\mathrm{C}$ ) 
(a)

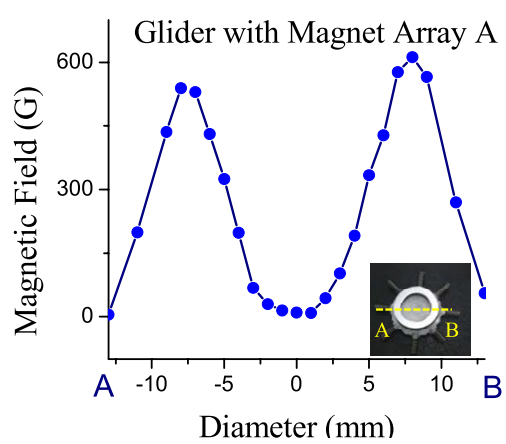

(b)

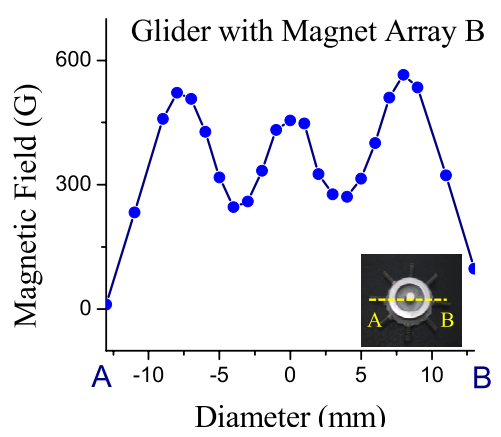

(c)

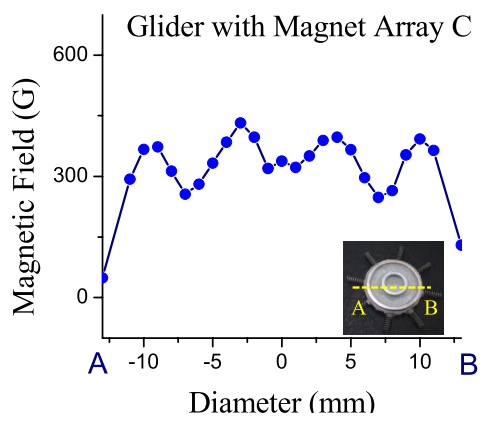

Fig. 7. The magnetic field produced by the magnet-array (a) A, (b) B, and (c) C fixed on the glider is measured at the location of the magnet fixed on the representative piezoelectric cantilever beam (i.e., measure the field experienced by the magnet fixed on the beam). The profile of the measured magnetic field is plotted along the line A-B of the glider shown in the inset of each figure.

experienced by the magnet fixed on the piezoelectric beam is slightly smaller than the array A and B. Thus, magnet-array C would cause a slightly smaller deflection of the beam resulting in a slightly smaller magnitude of the peak-to-peak voltageoutput than the magnet array A and B. Nevertheless, the converted frequency of the magnet-array $\mathrm{C}$ would be higher than the magnet-array A and B. Although these would influence the power-output of the harvester, all the magnet arrays are capable of increasing the oscillating frequency/cycles of the harvester through the frequency-conversion as we designed.

Fig. 8(a)-(b), (c)-(d), (e)-(f) is the illustration of the magnetarray $\mathrm{A}, \mathrm{B}$, and $\mathrm{C}$ fixed on the glider and the corresponding voltage-response of the harvester consisting of the magnetarray $\mathrm{A}, \mathrm{B}$, and $\mathrm{C}$ under the $\mathrm{x}$-axial (in-plane) vibration, respectively (note: for the in-plane vibration, the frequency and acceleration of the shaker is $7 \mathrm{~Hz}$ and $2.3 \mathrm{~g}$, respectively). In Fig. 8(b), 8(d), and 8(f), the maximum peak-topeak voltage-output of the magnet array $\mathrm{A}, \mathrm{B}$, and $\mathrm{C}$ is approximate $800 \mathrm{mV}, 800 \mathrm{mV}$, and $250 \mathrm{mV}$. We noticed that the magnitude of the voltage response of the magnet array $\mathrm{C}$ (see Fig. 8(f)) is smaller than other array. This is explained by following. Because the volume of the ring magnets of magnet array $\mathrm{C}$ is smaller than other magnet arrays, the peak-topeak magnitude of the magnetic-field generated by the magnet array C (see Fig. 7(c)) is smaller than other arrays (as shown in Fig. 7(a) and 7(b)). This results in a smaller magnetic repulsive force interaction between the magnet on the beam and magnet array on the glider in the case of magnet array $\mathrm{C}$ than the other arrays. The smaller force interaction causes a smaller deflection of the beam. Due to the piezoelectric effect, a smaller deflection of the beam in the case of magnet array $\mathrm{C}$ produces a smaller voltage response when compared with other magnet arrays. Nevertheless, all of the voltage responses indicate that the harvester using any of the magnet arrays we designed is capable of harnessing the energy from the x-axial (in-plane) motion/vibration. In addition to energy harvesting, we observed the ambient incoming (input) frequency of $7 \mathrm{~Hz}$ is converted by the harvester using the magnet array $\mathrm{A}, \mathrm{B}$, and $\mathrm{C}$ to a higher frequency of $28 \mathrm{~Hz}, 42 \mathrm{~Hz}$, and $56 \mathrm{~Hz}$ as shown in Fig. 8(b), 8(d), and 8(f), respectively. This shows the oscillating frequency of the harvester using any of the magnet arrays is successfully increased through the frequency conversion. The most important is, by arranging the elements in magnet arrays, the oscillating frequency of the harvester is precisely converted (refer Fig. 2 for our design: ambient incoming lower vibration frequency $\mathrm{x}$ number of magnetic elements on the glider passing beneath the piezoelectric beam $=$ converted frequency). This is proved by following. The marked numbers in Fig. 8(a), 8(c), and 8(e) illustrate an interacting sequence that the element of the magnet array of the glider translating exactly beneath the piezoelectric beam in one oscillating cycle. The voltage outputs correlated to these numbers in the sequence are marked in Fig. 8(b), 8(d), and 8(f). For instant, in the case of magnet-array A, when the glider translates from left to right, and to left (in one oscillating cycle at $7 \mathrm{~Hz}$ ), the element/part of the magnet ring on the glider will translate exactly beneath the beam 4 times (in the sequence numbered from 1 to 4 as shown in Fig. 8(a)) due to the geometric configuration of the magnet ring.

Hence, the beam is deflected by the magnetic force interaction produced between the magnet fixed on the beam and the element/part of the magnetic ring fixed on the glider. Consequently, voltage-response is produced 4 times as the sequence numbered from 1 to 4 as shown in Fig. 8(b). Therefore, as shown in Fig. 8(a)-(b), the ambient lower incoming (input) frequency of $7 \mathrm{~Hz}$ is converted by the harvester using the magnet array A (number of magnetic elements on the glider passing beneath the piezoelectric beam is 4) to a higher frequency of $28 \mathrm{~Hz}$. This result proves our design (our design: ambient incoming lower vibration frequency $\mathrm{x}$ number of magnetic elements on the glider passing beneath the piezoelectric beam = converted frequency). In the case of magnet-array $\mathrm{B}$ and $\mathrm{C}$, three and four elements/parts of the magnet array translate beneath the beam in a sequence numbered from 1 to 6 and from 1 to 8 (as shown in Fig. 8(c) and $8(\mathrm{e})$ ) due to the geometry-configuration we designed, respectively. Therefore, voltage response is produced six and eight times in a sequence numbered from 1 to 6 and from 1 to 8 as shown in Fig. 8(d) and 8(f), respectively. Thus, as shown in Fig. 8(c)-(d) and 8(e)-(f), the ambient lower incoming (input) frequency of $7 \mathrm{~Hz}$ is converted by the harvester using the magnet array A and B (number of magnetic elements on the 
(a)

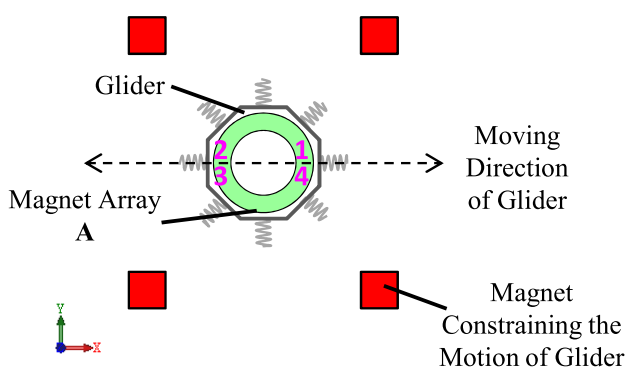

(b)

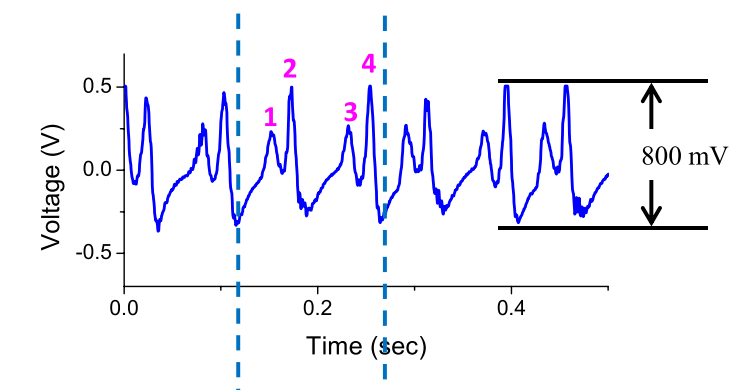

(c)

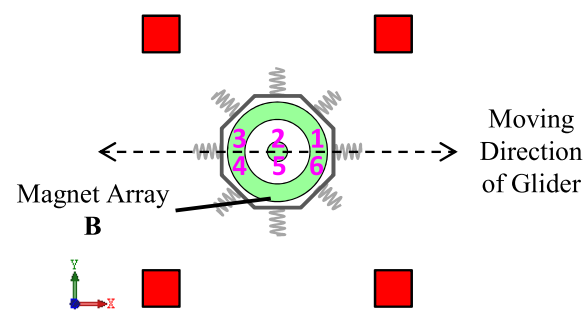

(d)

d)

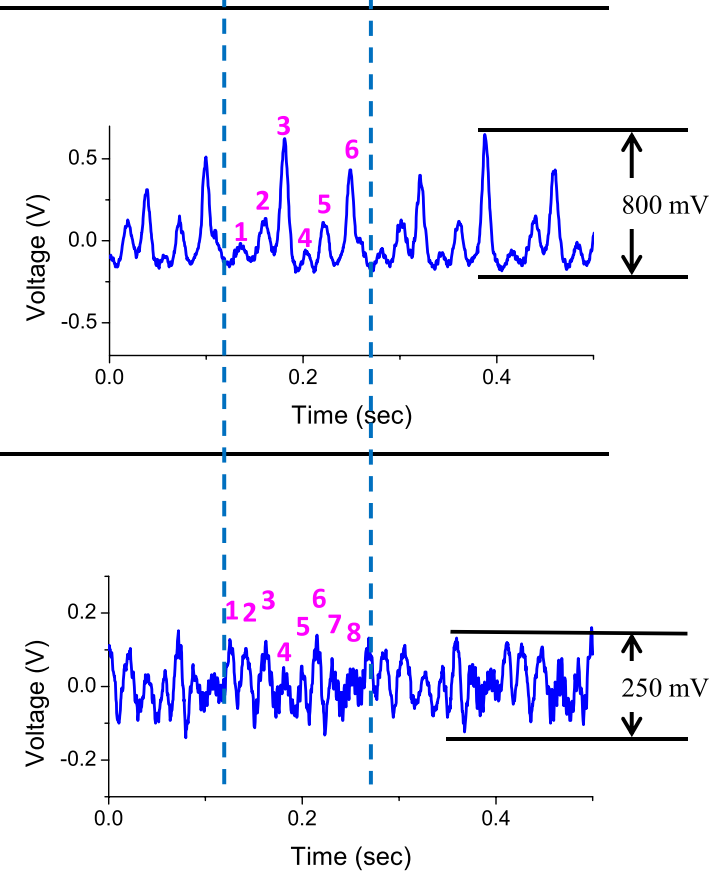

Fig. 8. Testing results of the harvester utilizing different magnet array under the $\mathrm{x}$-axial in-plane vibration (input: sine wave, $7 \mathrm{~Hz}, 2.3 \mathrm{~g}$ ). (a) The illustration and (b) corresponding voltage response of the harvester using magnet array A fixed on the glider. (c)-(d) and (e)-(f) The illustration and voltage response of the case using magnet array B and C, respectively. In figure (a), (c), and (e), these marked numbers illustrate an interacting sequence that the part of the glider translating exactly beneath the piezoelectric beam in one oscillating cycle. The voltage outputs correlated to these numbers in the sequence are marked in figure (b), (d), and (f).

glider passing beneath the piezoelectric beam is 6 and 8) to a higher frequency of 42 and $56 \mathrm{~Hz}$, respectively. These results validate our design again. To sum up, the frequencyconverting we observed from the case of magnet array A, B and $\mathrm{C}$ are the same in fundamental. Thus, we can conclude that the frequency converting is precisely controlled when the geometry-configuration of the magnet array on the glider is well-arranged. In addition, there is no discrepancy between the expected (designed) and experimental converted-frequency in each testing cases. This indicates, by modifying the magneticforce-configuration (such as changing the configuration and arrangement of magnet arrays, etc.), the converted frequency of the harvester under the X-axial (in-plane) vibration is tunable. Consequently, the voltage output of the harvester is controllable.

The result of harvester utilizing the three different magnet arrays under the vertical z-axial (out-of-plane) vibration is shown in Fig. 9. Fig. 9(a)-(c), 9(d)-(f), and 9(g)-(i) are the illustration, corresponding voltage response, and voltage pattern enlarged from the voltage response of the harvester using magnet array $\mathrm{A}, \mathrm{B}$, and $\mathrm{C}$, respectively. As shown in Fig. 9(c), 9(f), and 9(i), the maximum voltage output of the harvester using the magnet array $\mathrm{A}, \mathrm{B}$, and $\mathrm{C}$ under the z-axial (out-of-plane) vibration is $20 \mathrm{mV}, 27 \mathrm{mV}$, and $27 \mathrm{mV}$, respectively (note: for the out-of-plane vibration, the frequency and acceleration of the square wave provided by the shaker is $1 \mathrm{~Hz}$ and $3.5 \mathrm{~g}$, respectively). The results show the harvester using any of the three different magnet arrays we designed successfully harnesses the energy from the out-of-plane vibration. In addition to energy harvesting, the incoming lower vibration-frequency of $1 \mathrm{~Hz}$ for each case of magnet arrays using by the harvester is converted to a higher frequency of $294 \mathrm{~Hz}$ (i.e., is converted to resonate the beam with a resonant frequency of $294 \mathrm{~Hz}$ ). Although the detailed pattern of voltage response of the harvester using the three different magnet arrays under the z-axial (out-of-plane) vibration is slightly different, the frequency conversion is validated for all the cases of using the three different magnet arrays. Furthermore, 
(a)

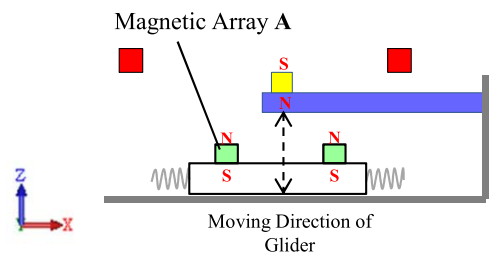

(b)

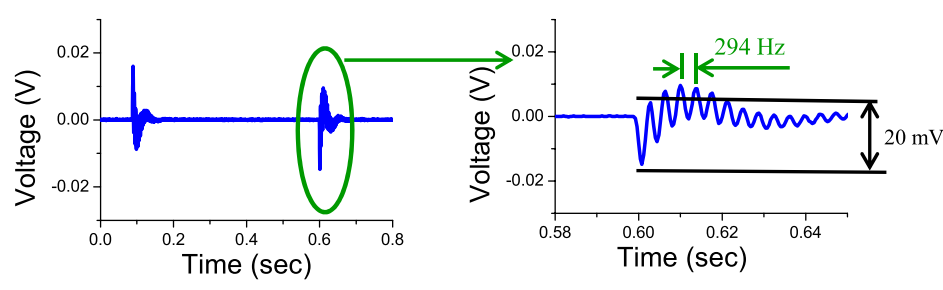

(d)

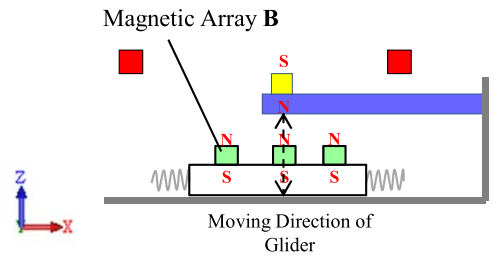

(e)

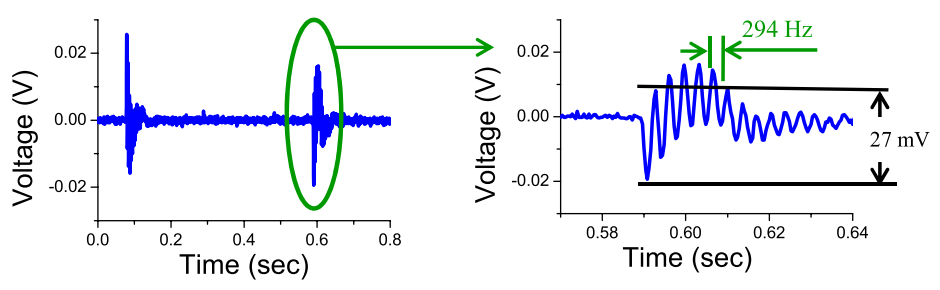

(g)

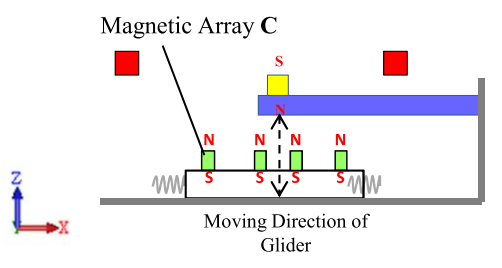

(h)

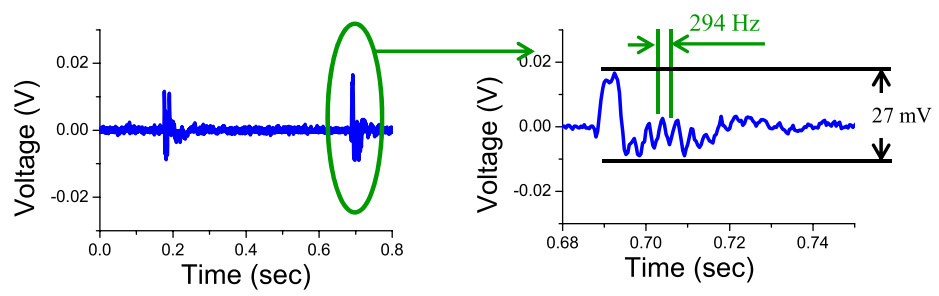

Fig. 9. Testing results of the harvester utilizing different magnet array under the z-axial out-of-plane vibration (input: Square-wave, $1 \mathrm{~Hz}, 3.5 \mathrm{~g}$ ). (a), (b), and (c) The illustration of the magnet array A fixed on the glider of the harvester under the vibration test, the corresponding voltage response, and the voltage pattern enlarged from the voltage response, respectively. (d)-(f) and (g)-(i) The illustration, voltage response, and enlarged voltage pattern of the case using magnet array $\mathrm{B}$ and $\mathrm{C}$, respectively.

there is not much discrepancy between the expected (designed) and experimental converted-frequency in each oscillating cycle for the harvester. This concludes that we can precisely control the frequency conversion for the harvester under the out-of-plane vibration. We also noticed that the detailed pattern of the voltage response of the harvester under the out-of-plane vibration (see Fig. 9(c), 9(f), and 9(i)) is influenced by the magnetic-force configuration (i.e., by the arrangement of the magnet array). This influence we observed from the out-of-plane vibration test is also occurred in the in-plane vibration test. Therefore, an optimization of the magnetic-force configuration for the harvester is needed in future.

The in-plane and out-of-plane vibration testing results shown in Figs. 8-9 are summarized in Table I. According to Table I, the maximum peak-to-peak voltage and root-mean-square voltage of the harvester under the in-plane vibration (along $\mathrm{x}$-axis, sine-wave, $7 \mathrm{~Hz}, 2.3 \mathrm{~g}$ ) is $800 \mathrm{mV}$ and $199 \mathrm{mV}$, respectively. Through the equation (Power $=$ Voltage $^{2} /$ Resistance) mentioned in the design section, the peak-to-peak power and averaged root-mean-square power is estimated as $640 \mathrm{nW}$ and $39.6 \mathrm{nW}$, respectively. Because the length, width, and thickness of the power-generating element of the harvester (i.e., PZT cantilever beam) is $20 \mathrm{~mm}$,
$3 \mathrm{~mm}$, and $250 \mu \mathrm{m}$, the power density (power-output per unit-volume) is calculated as $42.7 \mathrm{nW} / \mathrm{mm}^{3}$. Regarding to the harvester under the out-of-plane vibration test (along $\mathrm{z}$-axis, square-wave, $1 \mathrm{~Hz}, 3.5 \mathrm{~g}$ ), the maximum peak-topeak voltage and root-mean-square voltage of the harvester is $27 \mathrm{mV}$ and $7.1 \mathrm{mV}$. Repeating the estimation process mentioned above, the maximum peak-to-peak power, averaged root-mean-square power, and the power density is calculated as $0.729 \mathrm{nW}, 0.05 \mathrm{nW}$, and $0.049 \mathrm{nW} / \mathrm{mm}^{3}$.

Moreover, when we investigate the details of the in-plane vibration test results shown in Table $\mathrm{I}$, we note that both $\mathrm{P}_{\mathrm{pp}}$ of the harvester using magnet array $\mathrm{A}$ and $\mathrm{B}$ are the same due to the same $V_{p p}$ we obtained (both are $800 \mathrm{mV}$ ). This is explained below. First of all, the maximum magnetic field in Fig. 7(a) and Fig. 7(b) are almost the same (approximate 600 Gauss). This results the same magnetic force producing same $\mathrm{V}_{\mathrm{pp}}$ and $\mathrm{P}_{\mathrm{pp}}$ in both cases. Furthermore, the repulsive magnetic force in both cases are larger than the threshold force-value which pushes the PZT cantilever beam to reach the beam's maximum bending limitation. After the limitation is reached, increasing the magnetic repulsive force cannot increase the bending anymore. This confirms again that the $\mathrm{V}_{\mathrm{pp}}$ and $\mathrm{P}_{\mathrm{pp}}$ in both cases would the same. Furthermore, $\mathrm{V}_{\mathrm{pp}}$ in both cases $(800 \mathrm{mV})$ are higher than the $V_{p p}$ in the case 
TABLE I

SumMARY OF THE ENERGY-HARVESTING AND FREQUENCY-CONVERSION RESUltS OF OUR ENERGy HARVESTER

\begin{tabular}{|c|c|c|c|c|c|c|}
\hline \multirow{2}{*}{$\begin{array}{c}\text { Case } \\
\quad \\
\text { Input }\end{array}$} & \multicolumn{2}{|c|}{ Magnet Array A } & \multicolumn{2}{|c|}{ Magnet Array B } & \multicolumn{2}{|c|}{ Magnet Array C } \\
\hline & $\begin{array}{l}\text { Frequency- } \\
\text { Conversion }\end{array}$ & Electrical Output & $\begin{array}{l}\text { Frequency- } \\
\text { Conversion }\end{array}$ & Electrical Output & $\begin{array}{l}\text { Frequency- } \\
\text { Conversion }\end{array}$ & Electrical Output \\
\hline $\begin{array}{c}\text { In-plane Vibration } \\
\text { (Along X-axis) } \\
\text { Sine-wave } \\
7 \mathrm{~Hz} \\
2.3 \mathrm{~g}\end{array}$ & $\begin{array}{l}\text { Expected } \\
\text { (input } 7 \mathrm{~Hz} x \\
\text { factor 4) } \\
: 28 \mathrm{~Hz} \\
\\
\text { Result: } \\
28 \mathrm{~Hz}\end{array}$ & $\begin{array}{c}\mathrm{V}_{\mathrm{pp}}: 800 \mathrm{mV} \\
\mathrm{V}_{\mathrm{rms}}: 199 \mathrm{mV} \\
\mathrm{P}_{\mathrm{pp}}: 640 \mathrm{nW} \\
\mathrm{P}_{\mathrm{rms}}: 39.6 \mathrm{nW} \\
\mathrm{P}_{\mathrm{pp}} / \mathrm{vol}: 42.7 \mathrm{nW} / \mathrm{mm}^{3}\end{array}$ & $\begin{array}{l}\text { Expected } \\
\text { (input } 7 \mathrm{~Hz} x \\
\text { factor 6) } \\
\text { :42 Hz } \\
\\
\text { Result: } \\
42 \mathrm{~Hz}\end{array}$ & $\begin{array}{c}\mathrm{V}_{\mathrm{pp}}: 800 \mathrm{mV} \\
\mathrm{V}_{\mathrm{rms}}: 165 \mathrm{mV} \\
\mathrm{P}_{\mathrm{pp}}: 640 \mathrm{nW} \\
\mathrm{P}_{\mathrm{rms}}: 27.2 \mathrm{nW} \\
\mathrm{P}_{\mathrm{pp}} / \mathrm{vol}: 42.7 \mathrm{nW} / \mathrm{mm}^{3}\end{array}$ & $\begin{array}{c}\text { Expected } \\
\text { (input } 7 \mathrm{~Hz} \mathrm{x} \\
\text { factor } 8 \text { ) } \\
: 56 \mathrm{~Hz} \\
\\
\text { Result: } \\
56 \mathrm{~Hz}\end{array}$ & $\begin{array}{c}\mathrm{V}_{\mathrm{pp}}: 250 \mathrm{mV} \\
\mathrm{V}_{\mathrm{rms}}: 57 \mathrm{mV} \\
\mathrm{P}_{\mathrm{pp}}: 62.5 \mathrm{nW} \\
\mathrm{P}_{\mathrm{rms}}: 3.2 \mathrm{nW} \\
\mathrm{P}_{\mathrm{pp}} / \mathrm{vol}: 4.2 \mathrm{nW} / \mathrm{mm}^{3}\end{array}$ \\
\hline $\begin{array}{c}\text { Out-of-plane } \\
\text { Vibration } \\
\text { (Along Z-axis) } \\
\text { Square-wave } \\
1 \mathrm{~Hz} \\
3.5 \mathrm{~g}\end{array}$ & $\begin{array}{l}\text { Expected: } \\
294 \mathrm{~Hz} \\
\text { Result: } \\
294 \mathrm{~Hz}\end{array}$ & $\begin{array}{c}\mathrm{V}_{\mathrm{pp}}: 20 \mathrm{mV} \\
\mathrm{V}_{\mathrm{rms}}: 3.8 \mathrm{mV} \\
\mathrm{P}_{\mathrm{pp}}: 0.4 \mathrm{nW} \\
\mathrm{P}_{\mathrm{rms}}: 0.014 \mathrm{nW} \\
\mathrm{P}_{\mathrm{pp}} / \mathrm{vol}: 0.027 \mathrm{nW} / \mathrm{mm}^{3}\end{array}$ & $\begin{array}{l}\text { Expected: } \\
294 \mathrm{~Hz} \\
\text { Result: } \\
294 \mathrm{~Hz}\end{array}$ & $\begin{array}{c}\mathrm{V}_{\mathrm{pp}}: 27 \mathrm{mV} \\
\mathrm{V}_{\mathrm{rms}}: 7.1 \mathrm{mV} \\
\mathrm{P}_{\mathrm{pp}}: 0.729 \mathrm{nW} \\
\mathrm{P}_{\mathrm{rms}}: 0.05 \mathrm{nW} \\
\mathrm{P}_{\mathrm{pp}} / \mathrm{vol}: 0.049 \mathrm{nW} / \mathrm{mm}^{3}\end{array}$ & $\begin{array}{l}\text { Expected: } \\
294 \mathrm{~Hz} \\
\text { Result: } \\
294 \mathrm{~Hz}\end{array}$ & $\begin{array}{c}\mathrm{V}_{\mathrm{pp}}: 27 \mathrm{mV} \\
\mathrm{V}_{\mathrm{rms}}: 5.8 \mathrm{mV} \\
\mathrm{P}_{\mathrm{pp}}: 0.729 \mathrm{nW} \\
\mathrm{P}_{\mathrm{rms}}: 0.034 \mathrm{nW} \\
\mathrm{P}_{\mathrm{pp}} / \text { vol: } 0.049 \mathrm{nW} / \mathrm{mm}^{3}\end{array}$ \\
\hline $\begin{array}{l}\text { peak-to-peak volta } \\
\text { root-mean-square } \\
\text { Resistance: } 1 \mathrm{M} \Omega\end{array}$ & $\begin{array}{l}\text { tput } \\
\text { ge output }\end{array}$ & & $\begin{array}{l}\mathrm{P}_{\mathrm{rm}} \\
\mathrm{P}_{\mathrm{pp}}\end{array}$ & $\begin{array}{l}\text { eak-to-peak power outpr } \\
\text { root-mean-square power } \\
\text { ol: peak-to-peak power o }\end{array}$ & $\begin{array}{l}\text { atput } \\
\text { put per unit vo }\end{array}$ & e of one single beam \\
\hline
\end{tabular}

of the harvester using magnet array $\mathrm{C}(250 \mathrm{mV})$. This is attributed to that the maximum magnetic field in both cases (see Fig. 7(a) and Fig. 7(b); maximum approximate 600 Gauss) are much higher than that in the case of magnet array $\mathrm{C}$ (see Fig. 7(c); maximum approximate 400 Gauss). Corresponding to the voltage response, the $\mathrm{P}_{\mathrm{pp}}$ in both cases are higher than the $\mathrm{P}_{\mathrm{pp}}$ in the case of magnet array C. Due to these, we know the magnetic repulsive force produced by the magnet on the beam and magnet array on the glider should not necessary be very high. There is a threshold value of the magnetic repulsive force for the harvester. The threshold value can be estimated through parametric optimization in the future. We also note that even the $V_{p p}$ in the case of magnetic array $A$ and $B$ are the same, the detailed voltage pattern in both cases are different as shown in figure Fig. 8(b) and Fig. 8(d) (note: the discrepancy of the detailed voltage pattern is caused by the dynamic magnetic force interaction in practical energyharvesting process). Discrepancy in detailed voltage patterns in the cases indicates the $V_{\text {rms }}$ in the cases are different. This explains why we obtained the same $\mathrm{V}_{\mathrm{pp}}(800 \mathrm{mV})$ but with different $\mathrm{V}_{\mathrm{rms}}(199 \mathrm{mV}$ and $165 \mathrm{mV})$ in both cases. This also results in same $\mathrm{P}_{\mathrm{pp}}(640 \mathrm{nW})$ but with different $\mathrm{P}_{\mathrm{rms}}(39.6 \mathrm{nW}$ and $27.2 \mathrm{nW}$ ) in both cases.

Regarding the details of the out-of-plane vibration results shown in Table $I$ (and also Fig. 9), the induced $V_{p p}$ is $20 \mathrm{mV}, 27 \mathrm{mV}$, and $27 \mathrm{mV}$ for the case of using magnet array $\mathrm{A}, \mathrm{B}$, and $\mathrm{C}$, respectively. We note that the $\mathrm{V}_{\mathrm{pp}}$ in case A (i.e., $20 \mathrm{mV}$ ) is lower than that of case $\mathrm{B}$ and $\mathrm{C}$ (i.e., both are $27 \mathrm{mV}$ ). This can be attributed to the magnitude of the magnetic-field at the central region of magnet array (for instant, region ranging from $+5 \mathrm{~mm}$ to $-5 \mathrm{~mm}$ marked in the diameter axis in Fig. 7). During the energy harvesting shown in Fig. 9(a), Fig. 9(d) and Fig. 9(g), when the glider is projected toward the magnet on the beam, the magnetic repulsive force produced by magnet array to the magnet on the beam can be regarded as in proportional to the magnetic field at the central region of magnet array. As shown in Fig. 7, the magnetic field at central region of magnetic array A (i.e., approximate 0-150 Gauss) is lower than that of magnetic array B and C (i.e., both are approximate 300 Gauss). This means, the magnetic repulsive force pushing the magnet on the beam produced by the magnetic array $\mathrm{A}$ is lower than that of magnetic array $B$ and $C$ and, consequently, the induced $V_{p p}$ of the magnetic array A is lower than that of array B and C.

Therefore, the $\mathrm{P}_{\mathrm{pp}}$ of the magnetic array A (i.e., $0.4 \mathrm{nW}$ ) is lower than that of array B and C (i.e., $0.729 \mathrm{nW}$ ). Furthermore, we note that both $\mathrm{V}_{\mathrm{pp}}$ and $\mathrm{P}_{\mathrm{pp}}$ of the magnetic array $\mathrm{B}$ and $\mathrm{C}$ are the same. This is also attributed to the abovementioned threshold value of the magnetic force causing the beam reaching the maximum bending limitation. Moreover, even the $\mathrm{V}_{\mathrm{pp}}$ in the case of magnetic array $\mathrm{B}$ and $\mathrm{C}$ are the same, the detailed voltage pattern in both cases are different (as shown in Fig. 9(f) and Fig. 9(i)) resulting in different $V_{\text {rms }}$ in both cases. This is why we obtained the same $\mathrm{V}_{\mathrm{pp}}(27 \mathrm{mV})$ and $\mathrm{P}_{\mathrm{pp}}(0.729 \mathrm{nW})$ but with different $\mathrm{V}_{\mathrm{rms}}(7.1 \mathrm{mV}$ and $5.8 \mathrm{mV})$ and $\mathrm{P}_{\mathrm{rms}}(0.05 \mathrm{nW}$ and $0.034 \mathrm{nW})$ in both cases.

Furthermore, when the power-generation capability of the energy harvester under the in-plane and out-of-plane vibration are compared, we found out the power density from the in-plane/x-axial vibration tests (i.e., $\mathrm{P}_{\mathrm{pp}} / \mathrm{vol}$ : ranging from $4.2 \mathrm{nW} / \mathrm{mm}^{3}$ to $42.7 \mathrm{nW} / \mathrm{mm}^{3}$ ) is much higher than that from the out-of-plane/z-axial vibration test (i.e., $\mathrm{P}_{\mathrm{pp}} / \mathrm{vol}$ : ranging 
TABLE II

POWER-OUtPut COMPARISON OF OUR ENERgy HaRVESTER AND OtHer REPRESENTATIVE MECHANICAL ENERGy HaRVESTERS

\begin{tabular}{|c|c|c|c|c|c|c|}
\hline Parameter & $\begin{array}{c}{[34]} \\
\text { Kulah } \\
(2008)\end{array}$ & $\begin{array}{l}\text { Z6] } \\
\text { Zorlu } \\
\text { (2011) }\end{array}$ & $\begin{array}{c}{[27]} \\
\text { Tang } \\
(2011) \\
\end{array}$ & $\begin{array}{l}{[33]} \\
\text { Chung } \\
\text { (2007) }\end{array}$ & $\begin{array}{c}\text { Our Device } \\
\text { (Single PZT Beam) }\end{array}$ & $\begin{array}{c}\text { Our Device* } \\
\text { (Total } 12 \text { PZT Beams) }\end{array}$ \\
\hline $\begin{array}{c}\text { Power- } \\
\text { Generation } \\
\text { Element }\end{array}$ & Coil & Coil & $\begin{array}{l}\text { Piezoelectric } \\
\text { Material }\end{array}$ & $\begin{array}{l}\text { Piezoelectric } \\
\text { Material }\end{array}$ & Piezoelectric Material & Piezoelectric Material \\
\hline $\begin{array}{c}\text { Multi-Axial } \\
\text { Energy } \\
\text { Harvesting }\end{array}$ & $\begin{array}{c}\text { Only } \\
\text { Single-Axial }\end{array}$ & Only Single-Axial & Only Single-Axial & $\begin{array}{c}\text { Only } \\
\text { Single-Axial }\end{array}$ & Three-Axial & Three-Axial \\
\hline $\begin{array}{l}\text { Multi-Axial } \\
\text { Frequency } \\
\text { Conversion }\end{array}$ & $\begin{array}{c}\text { Only } \\
\text { Single-Axial }\end{array}$ & Only Single-Axial & Only Single-Axial & $\begin{array}{c}\text { Only } \\
\text { Single-Axial }\end{array}$ & Three-Axial & Three-Axial \\
\hline Wear-out Free & No & No & Yes & Yes & Yes & Yes \\
\hline $\begin{array}{c}\text { Power- } \\
\text { Generation } \\
\text { Element Size }\end{array}$ & $\begin{array}{c}10-50 \times 15 \times 0.4 \\
\mathrm{~mm}^{3}\end{array}$ & $9 \times 7.5 \times 0.5 \mathrm{~mm}^{3}$ & $\begin{array}{c}9 \times 1.3 \times 0.14 \mathrm{~mm}^{3} \\
\times 2\end{array}$ & $\begin{array}{c}10 \times 2.5 \times 0.1 \\
\mathrm{~mm}^{3 \mathrm{a}}\end{array}$ & $20 \times 3 \times 0.25 \mathrm{~mm}^{3}$ & $20 \times 3 \times 0.25 \mathrm{~mm}^{3} \times 12$ \\
\hline $\begin{array}{l}\text { Cantilever } \\
\text { Resonance } \\
\text { Frequency }\end{array}$ & $64 \mathrm{~Hz}$ & $394 \mathrm{~Hz}$ & $240 \mathrm{~Hz}$ & $330 \mathrm{~Hz}$ & $294 \mathrm{~Hz}$ & $294 \mathrm{~Hz}$ \\
\hline $\begin{array}{l}\text { Equivalent Load } \\
\text { Resistance }\end{array}$ & $325 \Omega$ & $3.6 \Omega^{\mathrm{d}}$ & $6.1 \mathrm{M} \Omega$ & $1 \mathrm{M} \Omega$ & $1 \mathrm{M} \Omega$ & $1 \mathrm{M} \Omega$ \\
\hline $\begin{array}{c}\text { Ambient } \\
\text { Vibration } \\
\text { Frequency }\end{array}$ & $\begin{array}{l}25 \mathrm{~Hz} \\
\text { g: N.A. }\end{array}$ & $\begin{array}{l}10 \mathrm{~Hz} \\
\text { g: N.A. }\end{array}$ & $\begin{array}{c}10 \mathrm{~Hz} \\
1 \mathrm{~g}\end{array}$ & $\begin{array}{l}10 \mathrm{~Hz} \\
\text { g: N.A. }\end{array}$ & $\begin{array}{l}7 \mathrm{~Hz}^{\mathrm{b}}, 1 \mathrm{~Hz}^{\mathrm{c}} \\
2.3 \mathrm{~g}^{\mathrm{b}}, 3.5 \mathrm{~g}^{\mathrm{c}}\end{array}$ & $\begin{array}{l}7 \mathrm{~Hz}^{\mathrm{b}}, 1 \mathrm{~Hz}^{\mathrm{c}} \\
2.3 \mathrm{~g}^{\mathrm{b}}, 3.5 \mathrm{~g}^{\mathrm{c}}\end{array}$ \\
\hline $\begin{array}{l}\text { Maximum } \\
\text { Voltage }\end{array}$ & $\begin{array}{l}\mathrm{V}_{\mathrm{pp}}=12 \mathrm{mV} \\
\mathrm{V}_{\mathrm{rms}}: \text { N.A. }\end{array}$ & $\begin{array}{l}\mathrm{V}_{\mathrm{pp}}=650 \mathrm{mV} \\
\mathrm{V}_{\mathrm{rms}}: \text { N.A. }\end{array}$ & $\begin{array}{l}\mathrm{V}_{\mathrm{pp}}=40 \mathrm{~V}^{\mathrm{a}} \\
\mathrm{V}_{\mathrm{rms}}: \text { N.A. }\end{array}$ & $\begin{array}{l}V_{\mathrm{pp}}=12 \mathrm{~V} \\
\mathrm{~V}_{\mathrm{rms}}: \text { N.A. }\end{array}$ & $\begin{aligned} \mathrm{V}_{\mathrm{pp}} & =800 \mathrm{mV}^{\mathrm{b}} \\
\mathrm{V}_{\mathrm{pp}} & =27 \mathrm{mV}^{\mathrm{c}} \\
\mathrm{V}_{\mathrm{rms}} & =199 \mathrm{mV}^{\mathrm{b}} \\
\mathrm{V}_{\mathrm{rms}} & =7.1 \mathrm{mV}^{\mathrm{c}}\end{aligned}$ & $\begin{array}{c}\mathrm{V}_{\mathrm{pp}}=9.6 \mathrm{~V}^{\mathrm{b}} \\
\mathrm{V}_{\mathrm{pp}}=324 \mathrm{mV}^{\mathrm{c}} \\
\mathrm{V}_{\mathrm{rms}}=2.39 \mathrm{~V}^{\mathrm{b}} \\
\mathrm{V}_{\mathrm{rms}}=85.2 \mathrm{mV}^{\mathrm{c}}\end{array}$ \\
\hline $\begin{array}{l}\text { Maximum } \\
\text { Power }\end{array}$ & $\begin{array}{l}\mathrm{P}_{\mathrm{pp}}=480 \mathrm{nW} \\
\mathrm{P}_{\mathrm{rms}}: \text { N.A. }\end{array}$ & $\begin{array}{c}\mathrm{P}_{\mathrm{pp}}: \text { N.A. } \\
\mathrm{P}_{\mathrm{rms}}=544.7 \mu \mathrm{W}\end{array}$ & $\begin{array}{l}\mathrm{P}_{\mathrm{pp}}=101.4 \mu \mathrm{W} \\
\mathrm{P}_{\text {rms: }} \text { N.A. }\end{array}$ & $\begin{array}{c}\quad P_{p p}= \\
0.14 \mathrm{~mW}^{\mathrm{a}} \\
\text { Prms: N.A. }\end{array}$ & $\begin{array}{c}\mathrm{P}_{\mathrm{pp}}=640 \mathrm{nW}^{\mathrm{b}} \\
\mathrm{P}_{\mathrm{pp}}=0.729 \mathrm{nW}^{\mathrm{c}} \\
\mathrm{P}_{\mathrm{rms}}=39.6 \mathrm{nW}^{\mathrm{b}} \\
\mathrm{P}_{\mathrm{rms}}=0.05 \mathrm{nW}^{\mathrm{c}}\end{array}$ & $\begin{array}{c}\mathrm{P}_{\mathrm{pp}}=92.16 \mu \mathrm{W}^{\mathrm{b}} \\
\mathrm{P}_{\mathrm{pp}}=104.98 \mathrm{nW}^{\mathrm{c}} \\
\mathrm{P}_{\mathrm{rms}}=5.7 \mu \mathrm{W}^{\mathrm{b}} \\
\mathrm{P}_{\mathrm{rms}}=7.2 \mathrm{nW}^{\mathrm{c}} \\
\end{array}$ \\
\hline Power Density & $\begin{array}{c}\mathrm{PD}_{\mathrm{pp}}=2.67 \\
\mathrm{nW} / \mathrm{mm}^{3} \mathrm{a} \\
\mathrm{PD}_{\text {rms }}: \text { N.A. }\end{array}$ & $\begin{array}{l}\text { PD }_{\text {pp: N.A. }} \\
\text { PD }_{\text {rms }}=184 \\
\mu \mathrm{W} / \mathrm{mm}^{3}\end{array}$ & $\begin{array}{c}\mathrm{PD}_{\mathrm{pp}}=30.95 \\
\mu \mathrm{W} / \mathrm{mm}^{3} \mathrm{a} \\
\mathrm{PD}_{\mathrm{rms}}: \text { N.A. }\end{array}$ & $\begin{array}{c}\mathrm{PD}_{\mathrm{pp}}=57.6 \\
\mu \mathrm{W} / \mathrm{mm}^{3 \mathrm{a}} \\
\mathrm{PD}_{\mathrm{rms}}: \text { N.A. }\end{array}$ & $\begin{array}{l}\mathrm{PD}_{\mathrm{pp}}=42.7 \mathrm{nW} / \mathrm{mm}^{3 \mathrm{~b}} \\
\mathrm{PD}_{\mathrm{pp}}=0.049 \mathrm{nW} / \mathrm{mm}^{3 \mathrm{c}} \\
\mathrm{PD}_{\mathrm{rms}}=2.64 \mathrm{nW} / \mathrm{mm}^{3 \mathrm{~b}} \\
\mathrm{PD}_{\mathrm{rms}}=3.33 \mathrm{pW} / \mathrm{mm}^{3 \mathrm{c}}\end{array}$ & $\begin{array}{c}\mathrm{PD}_{\mathrm{pp}}=512.4 \mathrm{nW} / \mathrm{mm}^{3 \mathrm{~b}} \\
\mathrm{PD}_{\mathrm{pp}}=0.59 \mathrm{nW} / \mathrm{mm}^{3 \mathrm{c}} \\
\mathrm{PD}_{\mathrm{rms}}=31.68 \mathrm{nW} / \mathrm{mm}^{3 \mathrm{~b}} \\
\mathrm{PD}_{\mathrm{rms}}=40 \mathrm{pW} / \mathrm{mm}^{3 \mathrm{c}}\end{array}$ \\
\hline
\end{tabular}

${ }^{a}$ Value estimated or extrapolated from data in reference.

${ }^{\mathrm{b}}$ Value for in-plane vibration.

${ }^{c}$ Value for out-of-plane vibration.

${ }^{\mathrm{d}}$ Resistance of the pick-up coil.

*The values of total 12 PZT beams are estimated from [40].

from $0.027 \mathrm{nW} / \mathrm{mm}^{3}$ to $0.049 \mathrm{nW} / \mathrm{mm}^{3}$ ). This feature is fundamentally the same as the 3 -axial capacitive accelerometer using single-mechanism which the $\mathrm{x}$-axial resolution is much higher than $\mathrm{z}$-axial resolution. Thus, it is difficult to improve the $\mathrm{z}$-axial power-generation capability to comparable with $\mathrm{x}$-axial capability, unless a better mechanism of the harvester is innovated.

Furthermore, we compared the power-generation capability of our energy harvester and other representative mechanical energy harvesters. The other harvesters we chose to be compared are based on the common features in our and other harvesters. The features are: (a) multi-axial energy harvesting, (b) multi-axial frequency-conversion, (c) using cantilever-beam to convert the mechanical vibration, and (d) device is in centimeter scale (excluding the real MEMS devices due to the different fabrication technology and different physical phenomenon in micro-science such as significant electrostatic-interaction and severe surface-tension issues). The comparison results are summarized in table II.

According to the Table II, the maximum peak-to-peak voltage of the energy harvester demonstrated by
$\mathrm{V}_{\mathrm{pp}}=$ peak-to-peak voltage.

$\mathrm{P}_{\mathrm{pp}}=$ peak-to-peak power.

$\mathrm{P}_{\mathrm{rms}}=$ root-mean-square power.

$\mathrm{PD}_{\mathrm{pp}}=$ peak-to-peak power density.

$\mathrm{PD}_{\mathrm{rms}}=$ root-mean-square power density

Kulah et al [34], Zorlu et al [36], Tang et al [27] and Chung et al [33] is $12 \mathrm{mV}, 650 \mathrm{mV}, 40 \mathrm{~V}$ and $12 \mathrm{~V}$, respectively. Through the equation (Power $=$ Voltage $^{2} /$ Resistance), the estimated power output of the Kulah, Zorlu, Tang and Chung's energy-harvester is $480 \mathrm{nW}\left(\mathrm{P}_{\mathrm{pp}}\right), 544.7 \mu \mathrm{W}\left(\mathrm{P}_{\mathrm{rms}}\right)$, $101.4 \mu \mathrm{W}\left(\mathrm{P}_{\mathrm{pp}}\right)$ and $0.14 \mathrm{~mW}\left(\mathrm{P}_{\mathrm{pp}}\right)$. Furthermore, the peak-to-peak power density (power-output per unit-volume) of Kulah, Zorlu, Tang and Chung's energy-harvester is calculated using peak-to-peak power output divided by the volume of the power-generating element (i.e., PZT-sheet or electromagnetic-coil; which is $180 \mathrm{~mm}^{3}, 33.75 \mathrm{~mm}^{3}$, $3.28 \mathrm{~mm}^{3}$ and $2.5 \mathrm{~mm}^{3}$, respectively). After estimation, the peak-to-peak power density (power-output per unitvolume) of Kulah, Zorlu, Tang and Chung's is $2.67 \mathrm{nW} / \mathrm{mm}^{3}$ ( $\mathrm{PD}_{\mathrm{pp}}$ ), $184 \mu \mathrm{W} / \mathrm{mm}^{3}$ ( $\mathrm{PD}_{\mathrm{rms}}$ ), $30.95 \mu \mathrm{W} / \mathrm{mm}^{3}$ ( $\mathrm{PD}_{\mathrm{pp}}$ ), and $57.6 \mu \mathrm{W} / \mathrm{mm}^{3}\left(\mathrm{PD}_{\mathrm{pp}}\right)$, respectively. Regarding to our energy harvester in this work, the maximum peak-to-peak power, averaged root-mean-square power, and power density of our harvester under the in-plane vibration and out-of-plane vibration is $640 \mathrm{nW}, 39.6 \mathrm{nW}, 42.7 \mathrm{nW} / \mathrm{mm}^{3}$ and $0.729 \mathrm{nW}$, $0.05 \mathrm{nW}, 0.049 \mathrm{nW} / \mathrm{mm}^{3}$, respectively. When compared the 
power density, we note that the power density of our harvester is only larger than Kulah's harvester but lower than other researchers' harvesters. Although the power density of our harvester is not high enough to compare with most current representative harvesters, our harvester achieves three-axial energy harvesting and three-axial frequency conversion while other harvesters cannot. In addition to these two achievements, our harvester is wear-out free while other harvesters would experience severe mechanical wear-out and impact during the operation. Wear-out free for mechanical energy harvesters enables a real perpetual self-powered (energy-harvester powered) wireless sensor.

To sum up, the in-plane and out-of-plane vibration testing results (shown in Figs. 8-9 and Tab. I) prove that the harvester has the capability to successfully convert the energy from 3-axial motion/vibration to the piezoelectric response (voltage output) and precisely tune the ambient vibration frequency to a high frequency (to increase the oscillating frequency of the harvester or resonate the harvester). Due to this, our harvester is able to use one single-mechanism to demonstrate energy-harvesting and frequency-conversion under a 3-D/ 3-axial motion/vibration, while other harvesters [34]-[38] are not capable. Moreover, our harvester using non-contact frequency-conversion avoids the wear-out problem which occurred in the harvesters utilizing contact-based frequency conversion. Finally, the results also show that the magneticforce configuration and the piezoelectric beam (i.e., varying the geometry, size, and arrangement of the magnets, changing the relative location between the magnet array fixed on the glider and the magnet fixed on the beam, changing the flexibility of the beam, using different beams with different power-density, and so on) determines the voltage/power output and converted frequency of the harvester. For instance, the converted frequency of the harvester is in proportional to the number of the magnets in the magnet arrays. In addition, different magnet array produces different magnetic repulsiveforce interaction between the magnet array fixed on the glider and the magnet fixed on the piezoelectric beam and consequently results in different voltage response and converted frequency. A more flexible beam with a higher piezoelectric power-density also increases the magnetic repulsive-force interaction and corresponding power output. Due to these, the harvester can be improved by parametrically optimizing in future (i.e., to obtain the best parameters in order to get the highest voltage response and converted frequency). Moreover, the harvester we fabricated can consist of more piezoelectric beams (at least 12 beams according to the Fig. 5). When the 12 beams are connected in series [40], the power output of the harvester under the in-plane and out-of-plane vibration can be increased one-order higher to several $\mu \mathrm{W}$ and $\mathrm{nW}$, respectively.

\section{CONCLUSION}

We successfully demonstrated a magnetic-force-configured 3-axial frequency-tunable piezoelectric energy harvester. Through the magnetic-force configuration, the harvester is capable of converting the 3-axial mechanical motion/vibration to the piezoelectric voltage-output (i.e., 3-axial energy- harvesting) and simultaneously converting the ambient incoming lower vibration-frequency to a higher frequency without mechanical wear-out (i.e., non-contact frequency-conversion). When the configuration is modified, the oscillating frequency of the harvester is tuned. Through frequency-tuning, the oscillating frequency of the harvester and the ambient vibrationfrequency are able to be matched to maximize the power output. In the future, the voltage/power output of the harvester can be increased by parametric optimizing of the magneticforce-configuration and through using a flexible piezoelectric beam with a higher power-density.

\section{REFERENCES}

[1] M. Johnson et al., "A comparative review of wireless sensor network mote technologies," in Proc. IEEE Sensors Conf., Christchurch, New Zealand, Oct. 2009, pp. 1439-1442.

[2] E. D. Zubiete, L. F. Luque, A. V. M. Rodriguez, and I. G. Gonzalez, "Review of wireless sensors networks in health applications," in Proc. Annu. Int. Conf. IEEE Eng. Med. Biol. Soc., Boston, MA, USA, Aug./Sep. 2011, pp. 1789-1793.

[3] F. Yu, A. Bilberg, and E. Stenager, "Wireless medical sensor measurements of fatigue in patients with multiple sclerosis," in Proc. Ann. Int. Conf. IEEE Eng. Med. Biol. Soc., Buenos Aires, Argentina, Aug./Sep. 2010, pp. 3763-3767.

[4] K. Arshak, E. Jafer, G. Lyons, D. Morris, and O. Korostynska, "A review of low-power wireless sensor microsystems for biomedical capsule diagnosis," Microelectron. Int., vol. 21, no. 3, pp. 8-19, 2004.

[5] P. K. Wright, D. A. Dornfeld, R. G. Hillaire, and N. K. Ota, "A wireless sensor for tool temperature measurement and its integration within a manufacturing system," in Proc. Trans. NAMRI/SME, 2006.

[6] F. Franceschini, M. Galetto, D. Maisano, and L. Mastrogiacomo, "A review of localization algorithms for distributed wireless sensor networks in manufacturing," Int. J. Comput. Integr. Manuf., vol. 22, no. 7, pp. 698-716, 2009.

[7] J. P. Lynch and K. J. Loh, "A summary review of wireless sensors and sensor networks for structural health monitoring," Shock Vibrat. Dig., vol. 38, no. 2, pp. 91-128, 2006.

[8] S. Roundy and P. K. Wright, "A piezoelectric vibration based generator for wireless electronics," Smart Mater. Struct., vol. 13, no. 5, pp. 1131-1142, Oct. 2004.

[9] S. P. Beeby et al., "A micro electromagnetic generator for vibration energy harvesting," J. Micromech. Microeng., vol. 17, no. 7 pp. 1257-1265, Jul. 2007.

[10] E. K. Reilly, F. Burghardt, R. Fain, and P. K. Wright, "Powering a wireless sensor node with a vibration-driven piezoelectric energy harvester," Smart Mater. Struct., vol. 20, no. 12, p. 125006, 2011.

[11] P. C.-P. Chao, "Energy harvesting electronics for vibratory devices in self-powered sensors," IEEE Sensors J., vol. 11, no. 12, pp. 3106-3121, Dec. 2011.

[12] Z. Y. Fan, R. X. Gao, and D. O. Kazmer, "Self-energized acoustic wireless sensor for pressure-temperature measurement in injection molding cavity," in Proc. IEEE Sensors Conf., Christchurch, New Zealand, Oct. 2009, pp. 65-68.

[13] T. K. Chung et al., "Self-powered wireless vibration-sensing system for machining monitoring," Proc. SPIE, vol. 8692, p. 86922U, Apr. 2013.

[14] P. D. Mitcheson, E. M. Yeatman, G. K. Rao, A. S. Holmes, and T. C. Green, "Energy harvesting from human and machine motion for wireless electronic devices," Proc. IEEE, vol. 96, no. 9, pp. 1457-1486, Sep. 2008.

[15] R. H. Bhuiyan, R. A. Dougal, and M. Ali, "A miniature energy harvesting device for wireless sensors in electric power system," IEEE Sensors J., vol. 10, no. 7, pp. 1249-1258, Jul. 2010.

[16] D. Zhu, S. P. Beeby, M. J. Tudor, N. M. White, and N. R. Harris, "Novel miniature airflow energy harvester for wireless sensing applications in buildings," IEEE Sensors J., vol. 13, no. 2, pp. 691-700, Feb. 2013.

[17] E. Sazonov, H. Li, D. Curry, and P. Pillay, "Self-powered sensors for monitoring of highway bridges," IEEE Sensors J., vol. 9, no. 11, pp. 1422-1429, Nov. 2009.

[18] K. M. Farinholt, N. Miller, W. Sifuentes, J. MacDonald, G. Park, and C. R. Farrar, "Energy harvesting and wireless energy transmission for embedded SHM sensor nodes," Struct. Health Monitor., vol. 9, no. 3 pp. 269-280, 2010. 
[19] V. Janicek and M. Husak, "Designing the 3D electrostatic microgenerator," J. Electrostatics, vol. 71, no. 3, pp. 214-219, 2013.

[20] A. Nimo, U. Mescheder, B. Muller, and A. S. A. Elkeir, "3D capacitive vibrational micro harvester using isotropic charging of electrets deposited on vertical sidewalls," Prague Czech Republic Proc. Smart Sens. Act. MEMS V, vol. 8066, p. 80661Q, May 2011.

[21] U. Mescheder, A. Nimo, B. Muller, and A. S. A. Elkeir, "Micro harvester using isotropic charging of electrets deposited on vertical sidewalls for conversion of 3D vibrational energy," Microsyst. Technol., vol. 18, nos. 7-8, pp. 931-943, 2012.

[22] D. B. Zhu, M. J. Tudor, and S. P. Beeby, "Strategies for increasing the operating frequency range of vibration energy harvesters: A review," Meas. Sci. Technol., vol. 21, no. 2, p. 022001, 2010.

[23] L. Tang, Y. Yang, and C. K. Soh, "Toward broadband vibration-based energy harvesting," J. Intell. Mater. Syst. Struct., vol. 21, no. 18, pp. 1867-1897, 2010

[24] J. Yang, Y. Wen, P. Li, X. Bai, and M. Li, "Improved piezoelectric multifrequency energy harvesting by magnetic coupling," in Proc. IEEE Sensors Conf., Limerick, Ireland Oct. 2011, pp. 28-31.

[25] L. Tang and Y. Yang, "A nonlinear piezoelectric energy harvester with magnetic oscillator," Appl. Phys. Lett., vol. 101, no. 9, pp. 094102-1-094102-4, 2012.

[26] Y. Zhu and J. W. Zu, "Enhanced buckled-beam piezoelectric energy harvesting using midpoint magnetic force," Appl. Phys. Lett., vol. 103, no. 4, pp. 041905-1-041905-4, 2013.

[27] Q. C. Tang, Y. L. Yang, and X. Li, "Bi-stable frequency up-conversion piezoelectric energy harvester driven by non-contact magnetic repulsion," Smart Mater. Struct., vol. 20, no. 12, pp. 125011-125016, 2011.

[28] A. M. Wickenheiser and E. Garcia, "Broadband vibration-based energy harvesting improvement through frequency up-conversion by magnetic excitation," Smart Mater. Struct., vol. 19, no. 6, pp. 065020-065030, 2010.

[29] A. Erturk, J. Hoffmann, and D. J. Inman, "A piezomagnetoelastic structure for broadband vibration energy harvesting," Appl. Phys. Lett., vol. 94, no. 25, pp. 254102-254105, 2009.

[30] S. F. Ali, S. Adhikari, M. I. Friswell, and S. Narayanan, "The analysis of piezomagnetoelastic energy harvesters under broadband random excitations," J. Appl. Phys., vol. 109, no. 7, p. 074904, 2011.

[31] S. Zhou, J. Cao, A. Erturk, and J. Lin, "Enhanced broadband piezoelectric energy harvesting using rotatable magnets," Appl. Phys. Lett. vol. 102, no. 17, pp. 173901-1-173901-4, 2013.

[32] X. Xing, J. Lou, G. M. Yang, O. Obi, C. Driscoll, and N. X. Sun, "Wideband vibration energy harvester with high permeability magnetic material," Appl. Phys. Lett., vol. 95, no. 13, pp. 134103-1-134103-3, 2009.

[33] T. K. Chung, D. G. Lee, M. Ujihara, and G. P. Carman, "Design, simulation, and fabrication of a novel vibration-based magnetic energy harvesting device," in Proc. 14th Int. Conf. Solid State Sens. Actuators Microsyst., Lyon, France, Jun. 2007, pp. 867-870.

[34] H. Kulah and K. Najafi, "Energy scavenging from low frequency vibrations by using frequency up conversion for wireless sensor applications," IEEE Sensors J., vol. 8, no. 3, pp. 261-268, Mar. 2008.

[35] I. Sari, T. Balkan, and H. Külah, "An electromagnetic micro power generator for low frequency environmental vibrations based on the frequency up-conversion technique," J. Microelectromech. Syst., vol. 19, no. 1, pp. 14-27, Feb. 2010.

[36] Ö. Zorlu, E. T. Topal, and H. Külah, "A vibration-based electromagnetic energy harvester using mechanical frequency up-conversion method," IEEE Sensors J., vol. 11, no. 2, pp. 481-488, Feb. 2011.

[37] T. Galchev, E. E. Aktakka, H. Kim, and K. Najafi, "A piezoelectric frequency-increased power generator for scavenging low-frequency ambient vibration," in Proc. IEEE 23rd Int. Conf. MEMS, Hong Kong, China, Jan. 2010, pp. 1203-1206.

[38] J. L. Fu, Y. Nakano, L. D. Sorenson, and F. Ayazi, "Multi-axis aln-on-silicon vibration energy harvester with integrated frequencyupconverting transducers," in Proc. IEEE 25th Int. Conf. MEMS, Paris, France, Jan./Feb. 2012, pp. 1269-1272.

[39] T. K. Chung, C. M. Wang, C. Y. Tseng, T. W. Liu, and P. C. Yeh, "A micro kinetic energy harvester demonstrating energy harvesting from 3-D mechanical motion and power increasing through magnetic-based frequency rectification," in Proc. ASME Conf. SMASIS, Mountain, GA, USA, 2012, pp. 853-858.

[40] I. C. Lien and Y. C. Shu, "Array of piezoelectric energy harvesting by the equivalent impedance approach," Smart Mater. Struct., vol. 21, no. 8, p. 082001, 2012.

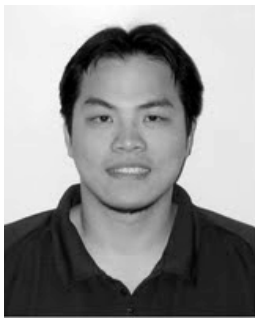

Tien-Kan Chung is an Assistant Professor with the Department of Mechanical Engineering, National Chiao Tung University (NCTU), Hsinchu, Taiwan. $\mathrm{He}$ received the Ph.D. degree in mechanical engineering from the University of California at Los Angeles, Los Angeles, CA, USA, in 2009, where he was also a Post-Doctoral Researcher in 2009. From 2009 to 2011, he was with the Department of MEMS Research and Development, Taiwan Semiconductor Manufacturing Company, Hsinchu. Since 2011, he has been at NCTU as a Faculty Member. His research interests are smart sensors, actuators, energy harvesters, MEMS, NEMS, and nanomagnetoelectrics.

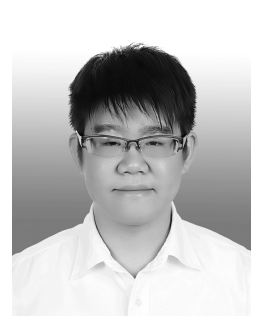

Chieh-Min Wang received the B.S. and M.S degrees in mechanical engineering from National Cheng Kung University, Tainan, Taiwan, and National Chiao Tung University, Hsinchu, in 2010 and 2013, respectively. His research interests are microenergy harvesters, MEMS, and semiconductor manufacturing technology. His M.S. thesis advisor was Dr. T.-K. Chung.

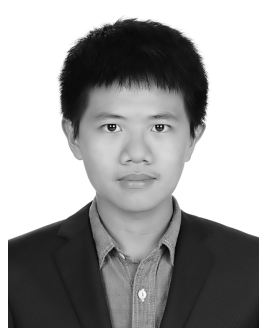

Po-Chen Yeh received the B.S. degree in mechanical engineering from National Chiao Tung University, Hsinchu, Taiwan, in 2013, where he is currently pursuing the Ph.D. degree at the Department of Mechanical Engineering. His Ph.D. advisor is Dr. T.-K. Chung. His research interests are nanomagnetoelectric coupling, smart materials, current sensors, MEMS, NEMS, wireless sensing.

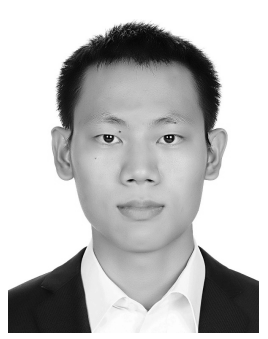

Tzu-Wei Liu received the B.S. degree in mechanical engineering from National Chiao Tung University, Hsinchu, Taiwan, in 2013, where he is currently pursuing the M.S. degree in mechanical engineering. His M.S. thesis advisor is Dr. T.-K. Chung. His research interests include energy harvesters, magnetomechanical-electrical coupling devices, and smart materials applications.

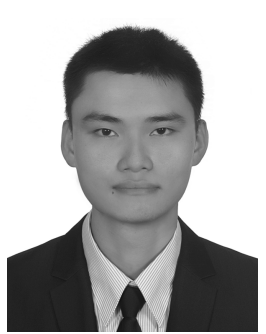

Chia-Yuan Tseng received the B.S. and M.S. degrees from the Department of Mold and Die Engineering, National Kaohsiung University of Applied Science and Mechanical Engineering, Kaohsiung, Taiwan, and National Chiao Tung University, Hsinchu, Taiwan, in 2011 and 2013, respectively. His M.S. thesis advisor was Dr. T.-K. Chung. His research interests are microenergy harvesters, MEMS, and semiconductor manufacturing technology.

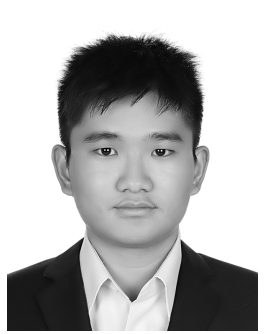

Chin-Chung Chen received the B.S. degree in mechanical engineering from National Chiao Tung University, Hsinchu, Taiwan, in 2013, where he is currently pursuing the Ph.D. degree in mechanical engineering. His Ph.D. advisor is Dr. T.-K. Chung. His research interests are applying magnetoelectric coupling in micro and nanoscale energy harvesters, NEMS, MEMS, and wireless sensing. 